Article

\title{
Palladium on Carbon-Catalyzed Suzuki-Miyaura Coupling Reaction Using an Efficient and Continuous Flow System
}

\author{
Tomohiro Hattori, Aya Tsubone, Yoshinari Sawama, Yasunari Monguchi * and Hironao Sajiki *
}

Laboratory of Organic Chemistry, Department of Organic and Medicinal Chemistry, Gifu Pharmaceutical University, 1-25-4 Daigaku-nishi, Gifu 501-1196, Japan;

E-Mails: 077002@gifu-pu.ac.jp (T.H.); 095059@gifu-pu.ac.jp (A.T.); sawama@gifu-pu.ac.jp (Y.S.)

* Authors to whom correspondence should be addressed; E-Mails: monguchi@gifu-pu.ac.jp (Y.M.); sajiki@gifu-pu.ac.jp (H.S.); Tel.: +81-58-230-8100 (Y.M.); +81-58-230-8109 (H.S.).

Academic Editor: Kei Manabe

Received: 19 October 2014 / Accepted: 26 December 2014 / Published: 12 January 2015

\begin{abstract}
The continuous flow Suzuki-Miyaura reaction between various haloarenes and arylboronic acids was successfully achieved within only ca. $20 \mathrm{~s}$ during the single-pass through a cartridge filled with palladium on carbon $(\mathrm{Pd} / \mathrm{C})$. No palladium leaching was observed in the collected reaction solution by atomic absorption spectrometry (detection limit: 1 ppm).
\end{abstract}

Keywords: flow reaction; ligand-free; palladium on carbon; single-pass; Suzuki-Miyaura coupling

\section{Introduction}

The palladium-catalyzed Suzuki-Miyaura coupling reaction between aryl halides and arylboronic acids is one of the most useful methodologies for the construction of a biaryl unit constituting a partial structure of some natural products, pharmaceuticals, and functional polymers, such as organic electroluminescence (EL) materials [1-3]. However, palladium metal as the active catalyst species should be removed from the product as an undesired waste after the reaction when the homogeneous catalyst was used. In addition to the effort and cost for the required removal process of the palladium waste, the unrecoverability of the expensive palladium catalysts is also a drawback. Therefore, 
the development of practical protocols for the Suzuki-Miyaura cross-coupling reaction is demanded from the perspective of green chemistry.

In the past few years, the use of heterogeneous flow systems in synthetic organic chemistry has become increasingly popular [4-7]. The systems use an apparatus for delivering a substrate solution into a cartridge filled with a heterogeneous catalyst. Since the flow channel in the catalyst cartridge passing the substrate solution is sufficiently narrow, the reaction efficiency should be enhanced due to the intimate contact of the catalyst with the substrate and reagents in comparison to a batch-type reaction using flasks or reaction vessels. The immobilized transition-metal catalyst, which often indicates a risk of ignition under atmospheric conditions, is enclosed in a completely-sealed cartridge during the flow-type reaction; hence, the reactions could be carried out in a safe manner. Furthermore, the removal of the metal residue from each reaction solution should not be necessary, and the catalyst can be reused unless metal leaching is observed. Taking great advantage of these features, we recently developed effective flow-type hydrogenation methods using several different types of catalysts possessing broad substrate applicabilities [8]. Several flow Suzuki-Miyaura cross-coupling reactions have also been reported using a heterogeneous catalyst $[6,9-11]$ as well as a homogeneous catalyst [6,12-15]. The supports for the heterogeneous palladium catalysts included a polyionic polymer [9], phosphine ligand-functionalized silica [10], activated carbon [11], and alumina [11]. Although the heterogeneous flow Suzuki-Miyaura coupling reactions in these reports efficiently proceeded, there is still room for improvement; thus, the reaction solution was continuously passed through the catalyst cartridge many times in the closed circulation reaction system to complete the reaction in the case of polyionic polymer-supported palladium [9]. The palladium catalyst on phosphine ligand-functionalized silica is commercially available but rather expensive [10]; high temperature $\left(150^{\circ} \mathrm{C}\right)$ and excess amount of base ( 3 equiv) were applied in the preceding paper by Mateos et al. using readily available $10 \% \mathrm{Pd} / \mathrm{C}$ or $10 \% \mathrm{Pd} / \mathrm{Al}_{2} \mathrm{O}_{3}$ as a catalyst [11]. An efficient batch-type ligand-free Suzuki-Miyaura coupling reaction catalyzed by $\mathrm{Pd} / \mathrm{C}$ at room temperature in aqueous media has been developed in our laboratory [16]. In this paper, we have demonstrated a practical protocol for the ligand-free $\mathrm{Pd} / \mathrm{C}$-catalyzed flow Suzuki-Miyaura reaction under mild conditions $\left(25-100^{\circ} \mathrm{C}\right)$, which is completed within only $20 \mathrm{~s}$ during the single-pass of the substrate solution through the catalyst cartridge.

\section{Results and Discussion}

We first investigated the flow rate of the $10 \% \mathrm{Pd} / \mathrm{C}$-catalyzed Suzuki-Miyaura cross-coupling between 4-iodoacetophenone $(1 \mathrm{mmol})$ and phenylboronic acid $(1.1 \mathrm{mmol})$ in the presence of sodium carbonate $\left(\mathrm{Na}_{2} \mathrm{CO}_{3}, 1.5 \mathrm{mmol}\right)$ in $\mathrm{EtOH} / \mathrm{H}_{2} \mathrm{O}(10 \mathrm{~mL} / 10 \mathrm{~mL})$ (Table 1). The 4-iodoacetophenone solution in $\mathrm{EtOH} / \mathrm{Et}_{2} \mathrm{O}(v / v=1: 1,0.05 \mathrm{M})$ was passed through the catalyst cartridge (ca. $0.3 \mathrm{~mL}$ inside volume) only once at $1 \mathrm{~mL} / \mathrm{min}, 2 \mathrm{~mL} / \mathrm{min}$, or $3 \mathrm{~mL} / \mathrm{min}$ and $25^{\circ} \mathrm{C}$, and the temperature was increased in incremental steps $\left(50{ }^{\circ} \mathrm{C}, 75^{\circ} \mathrm{C}\right.$, then $\left.100^{\circ} \mathrm{C}\right)$ when the reaction was incomplete at the lower step. The reaction progress was impeded by the flow rate faster than $1 \mathrm{~mL} / \mathrm{min}$ (Entries $1 \mathrm{vs.} 2$ and 4), and some of the 4-iodoacetophenone (1) remained unreacted $(6 \%)$ even at $100{ }^{\circ} \mathrm{C}$ in the case of the $3 \mathrm{~mL} / \mathrm{min}$ flow rate (Entry 5). Furthermore, the amount of $\mathrm{Na}_{2} \mathrm{CO}_{3}$ could be hardly decreased from 1.5 equiv at room temperature (Entries 1 vs. 6 and 7). Since it takes only approximately $20 \mathrm{~s}$ for the substrate solution 
to move through the catalyst cartridge even at the $1 \mathrm{~mL} / \mathrm{min}$ flow rate, the following investigations were carried out using 3 equiv of $\mathrm{Na}_{2} \mathrm{CO}_{3}$ at the $1 \mathrm{~mL} / \mathrm{min}$ flow rate.

Table 1. Flow rate and base use study.

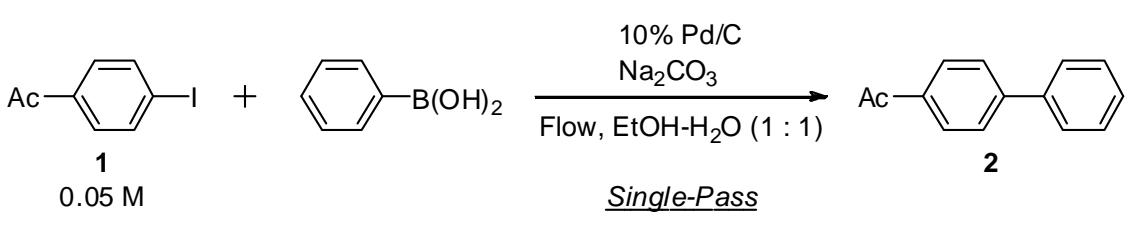

\begin{tabular}{ccccc}
\hline Entry & Flow rate (mL/min) & $\begin{array}{c}\text { Temperature } \\
\left({ }^{\circ} \mathbf{C}\right)\end{array}$ & $\mathbf{N a}_{2} \mathbf{C O}_{3}$ (equiv) & $\begin{array}{c}{ }^{\mathbf{1}} \mathbf{H} \mathbf{N M R} \text { ratio } \\
\mathbf{1 : 2}\end{array}$ \\
\hline 1 & 1 & 25 & 1.5 & $0: 100(100)^{\mathrm{a}}$ \\
2 & 2 & 25 & 1.5 & $21: 79$ \\
3 & 2 & 100 & 1.5 & $0: 100$ \\
4 & 3 & 25 & 1.5 & $32: 68$ \\
5 & 3 & 100 & 1.5 & $6: 94$ \\
6 & 1 & 25 & 1.2 & $56: 44$ \\
7 & 1 & 25 & 1.0 & $100: 0$ \\
\hline \multicolumn{5}{c}{} \\
\end{tabular}

The general applicability of iodo- and bromobenzenes to the present flow cross-coupling reaction was evaluated (Table 2, Figure S1). Electron-deficient iodobenzenes bearing an acetyl or ethoxycarbonyl group on the benzene nucleus were smoothly cross-coupled with phenylboronic acid at 25 or $75{ }^{\circ} \mathrm{C}$ to afford the corresponding biaryls in good yields (Entries 1-3). The phenylation of the electron-sufficient methyl- or methoxy-substituted iodobenzene with phenylboronic acid was completed at $75{ }^{\circ} \mathrm{C}$ (Entries 4 and 5). Besides phenylboronic acid, both the 3-and 4-acetylphenylboronic acids could be used for the present cross-coupling with aryl iodides in nearly quantitative yields (Entries 6-8). Although the reactivity of the 4-methoxyphenylboronic acid was slightly lower compared to an unsubstituted phenylboronic acid and the 3- and 4-acetylphenylboronic acids, the application of heat resulted in completion of the reaction (Entries 1, 2, 4, 6 and 7 vs. 9-11). Iodotoluenes were found to be good substrates regardless of the substitution pattern on the aromatic nucleus (Entries 11-13). The cross-coupling of 2,4-dimethoxyphenylboronic acid with 4-iodoanisole also well proceeded in spite of the bulkiness of a methoxy group on the aromatic ring of phenylboronic acid adjacent to the coupling site and the electron sufficient property (Entry 14). The bromoarenes bearing an electron-withdrawing substituent on the aromatic nucleus could also be applied to the present $10 \% \mathrm{Pd} / \mathrm{C}$-catalyzed flow Suzuki-Miyaura reaction under the one-pass operating conditions (Entries 15-18).

The $\mathrm{Pd}$ leaching from $10 \% \mathrm{Pd} / \mathrm{C}$ into the reaction solution during the present flow cross-coupling reaction between 4-iodoacetophenone $(10 \mathrm{mmol})$ and phenylboronic acid (1.1 equiv) at room temperature was measured by atomic absorption spectrometry (Table 3, Figure S2). No leached palladium species was detected in both the organic and aqueous layers after the phase separation due to the addition of EtOAc and $\mathrm{H}_{2} \mathrm{O}$ to the collected reaction solution $(<1 \mathrm{ppm}$ detection limit) (Entries 1 and 2) [17]. It would be mechanistically impossible to prevent the leaching of palladium into the collected reaction solution from the immobilized catalysts under the flow cross-coupling reaction conditions, since Pd(II) species, which are generated by the oxidative addition of haloarenes to $\operatorname{Pd}(0)$ metals on the support, 
should be separated from the support and flown out with solvent, as well-discussed in the reference [17]. In the present case, the reaction was carried out at $25^{\circ} \mathrm{C}$, very slow flow rate of the reaction mixture $(1 \mathrm{~mL} / \mathrm{min})$, and low substrate concentration $(0.05 \mathrm{M})$. These conditions may be reasons why the palladium leaching was not observed, although a possible low sensitivity for the detection could not be completely excluded.

Table 2. Scope of Substrate.

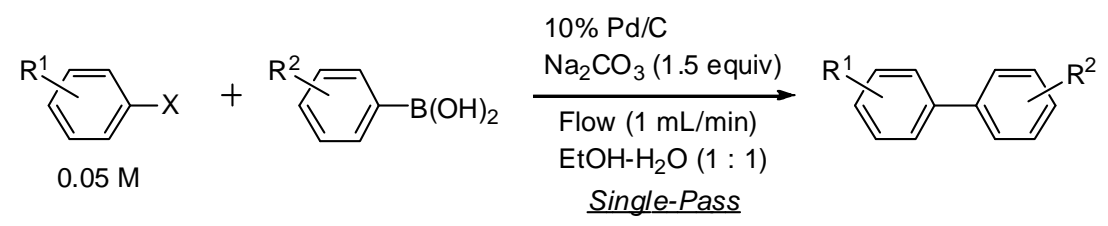

\begin{tabular}{cccccc}
\hline Entry & $\boldsymbol{X}$ & $\boldsymbol{R}^{\mathbf{1}}$ & $\boldsymbol{R}^{\mathbf{2}}$ & Temperature $\left({ }^{\circ} \mathbf{C}\right)$ & Yield (\%) $^{\mathbf{a}}$ \\
\hline $1[9]$ & $\mathrm{I}$ & $4-\mathrm{Ac}$ & $\mathrm{H}$ & 25 & 100 \\
$2[16]$ & $\mathrm{I}$ & $4-\mathrm{CO}_{2} \mathrm{Et}$ & $\mathrm{H}$ & 25 & 92 \\
$3[18]$ & $\mathrm{I}$ & $2-\mathrm{CO}_{2} \mathrm{Et}$ & $\mathrm{H}$ & 75 & 88 \\
$4[9]$ & $\mathrm{I}$ & $4-\mathrm{Me}$ & $\mathrm{H}$ & 75 & 91 \\
$5[16]$ & $\mathrm{I}$ & $4-\mathrm{OMe}$ & $\mathrm{H}$ & 75 & 81 \\
$6[19]$ & $\mathrm{I}$ & $4-\mathrm{Ac}$ & $3-\mathrm{Ac}$ & 25 & 99 \\
$7[18]$ & $\mathrm{I}$ & $4-\mathrm{CO}_{2} \mathrm{Et}$ & $4-\mathrm{Ac}$ & 25 & 91 \\
$8[9]$ & $\mathrm{I}$ & $4-\mathrm{OMe}$ & $4-\mathrm{Ac}$ & 75 & 97 \\
$9[9]$ & $\mathrm{I}$ & $4-\mathrm{Ac}$ & $4-\mathrm{OMe}$ & 50 & 89 \\
$10[18]$ & $\mathrm{I}$ & $4-\mathrm{CO}_{2} \mathrm{Et}$ & $4-\mathrm{OMe}$ & 75 & 97 \\
$11[20]$ & $\mathrm{I}$ & $4-\mathrm{Me}$ & $4-\mathrm{OMe}$ & 75 & 100 \\
$12[21]$ & $\mathrm{I}$ & $3-\mathrm{Me}$ & $4-\mathrm{OMe}$ & 75 & 98 \\
$13[21]$ & $\mathrm{I}$ & $2-\mathrm{Me}$ & $4-\mathrm{OMe}$ & 75 & 98 \\
$14[22]$ & $\mathrm{I}$ & $4-\mathrm{OMe}$ & $2,4-$ di-OMe & 100 & 78 \\
$15[9]$ & $\mathrm{Br}$ & $4-\mathrm{Ac}$ & $\mathrm{H}$ & 50 & 90 \\
$16[16]$ & $\mathrm{Br}$ & $4-\mathrm{CO}_{2} \mathrm{Et}$ & $\mathrm{H}$ & 100 & 78 \\
$17[9]$ & $\mathrm{Br}$ & $4-\mathrm{Ac}$ & $4-\mathrm{OMe}$ & 50 & 97 \\
$18[18]$ & $\mathrm{Br}$ & $4-\mathrm{CO}_{2} \mathrm{Et}$ & $4-\mathrm{OMe}$ & 75 & 100 \\
\hline & & & ${ }^{a}$ Isolate yield.
\end{tabular}

Table 3. Leaching test of the Pd.

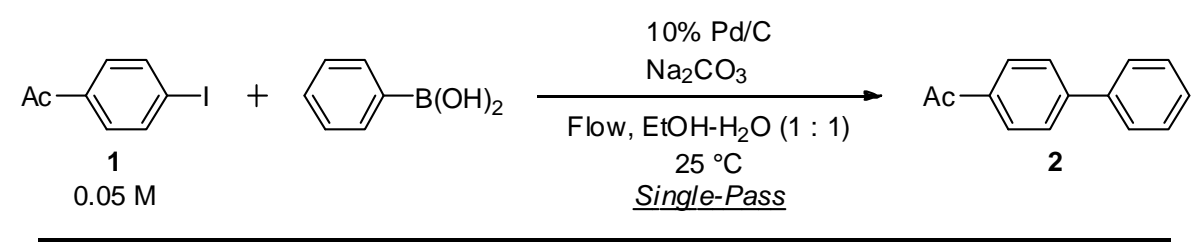

\begin{tabular}{cccc}
\hline Entry & Layer & $\begin{array}{c}{ }^{1} \text { H NMR ratio } \\
\mathbf{1 : 2}\end{array}$ & Pd leaching \\
\hline 1 & Organic & $0: 100(99)^{\mathrm{a}}$ & $<1 \mathrm{ppm}$ \\
2 & Aquous & $<1 \mathrm{ppm}$ \\
\hline \multicolumn{4}{c}{${ }^{\mathrm{a}}$ Isolate yield. }
\end{tabular}




\section{Experimental Section}

\subsection{General Procedure}

All reagents and solvents were obtained from commercial sources and used without further purification. $10 \% \mathrm{Pd} / \mathrm{C}$ (dry type) was obtained from the N.E. Chemcat Co. (Tokyo, Japan). The ${ }^{1} \mathrm{H}$ NMR spectra were measured by a JEOL (Tokyo, Japan) JMN AL-400 spectrometer (400 MHz for ${ }^{1} \mathrm{H}$ NMR and $100 \mathrm{MHz}$ for ${ }^{13} \mathrm{C} \mathrm{NMR}$ ) in $\mathrm{CDCl}_{3}$ as the solvent. Chemical shifts $(\delta)$ were expressed in ppm and internally referenced $\left(0.00 \mathrm{ppm}\right.$ for tetramethylsilane/ $\mathrm{CDCl}_{3}$ for ${ }^{1} \mathrm{H} \mathrm{NMR}$ and $77.0 \mathrm{ppm}$ for $\mathrm{CDCl}_{3}$ for ${ }^{13} \mathrm{C}$ NMR). Mass spectra (EI) were taken by a JEOL (Tokyo, Japan) JMS Q1000GC Mk II Quad GC/MS. All products are known compounds.

\subsection{Typical Procedure for the Palladium on Carbon-Catalyzed Cross-Coupling Reaction under Flow Conditions}

A solution of $\mathrm{Na}_{2} \mathrm{CO}_{3}(159 \mathrm{mg}, 1.50 \mathrm{mmol})$ in water $(10 \mathrm{~mL})$ was mixed with a solution of aryl halide $(1.00 \mathrm{mmol})$ and arylboronic acid $(1.10 \mathrm{mmol})$ in $\mathrm{EtOH}(10 \mathrm{~mL})$. The resulting solution was passed though the catalyst-packed cartridge $(10 \% \mathrm{Pd} / \mathrm{C}(99.4 \mathrm{mg}) ; 30 \mathrm{~mm}$ long-cartridge, ca. $0.3 \mathrm{~mL}$ internal volume) once at $1 \mathrm{~mL} / \mathrm{min}$ at $25,50,75$, or $100^{\circ} \mathrm{C}$ using H-Cube ${ }^{\circledR}$ (ThalesNano Nanotechnology, Inc., Budapest, Hungary) as the flow reactor. The collected reaction solution was diluted with $\mathrm{H}_{2} \mathrm{O}(10 \mathrm{~mL})$ and EtOAc $(10 \mathrm{~mL})$, and separated into two layers. The aqueous layer was extracted with EtOAc $(2 \times 10 \mathrm{~mL})$ and the combined organic layers were washed with brine $(10 \mathrm{~mL})$, dried over $\mathrm{MgSO}_{4}$, and concentrated in vacuo. The residue was purified by silica gel column chromatography (Hexane/EtOAc, 10:1) to give the analytically-pure coupling product. The ${ }^{1} \mathrm{H}$ NMR spectra of the products were identical to those in the literature; see supplementary information.

\subsection{Leaching Test of Palladium (Table 3)}

A solution of $\mathrm{Na}_{2} \mathrm{CO}_{3}(1.59 \mathrm{~g}, 15.0 \mathrm{mmol})$ in water $(100 \mathrm{~mL})$ was mixed with a solution of 4'-iodoacetophenone (2.46 g, $10.0 \mathrm{mmol})$ and phenylboronic acid $(1.34 \mathrm{~g}, 11.0 \mathrm{mmol})$ in EtOH $(100 \mathrm{~mL})$. The resulting solution was passed though the catalyst-packed cartridge $(10 \% \mathrm{Pd} / \mathrm{C}(99.4 \mathrm{mg}) ; 30 \mathrm{~mm}$ long-cartridge, ca. $0.3 \mathrm{~mL}$ internal volume) once at $1 \mathrm{~mL} / \mathrm{min}$ at $25{ }^{\circ} \mathrm{C}$ using $\mathrm{H}-\mathrm{Cube}{ }^{\circledR}$ (ThalesNano Nanotechnology, Inc., Budapest, Hungary) as a flow reactor. The collected reaction solution was diluted with $\mathrm{H}_{2} \mathrm{O}(20 \mathrm{~mL})$ and EtOAc $(20 \mathrm{~mL})$, and separated into two layers. The aqueous layer was further extracted with EtOAc $(2 \times 20 \mathrm{~mL})$, and the combined organic layers were washed with brine $(10 \mathrm{~mL})$, and dried over $\mathrm{MgSO}_{4}$. The resulting dried solution was concentrated in vacuo and transferred to a 100-mL volumetric flask. Then, $\mathrm{MeOH}$ was added to $100 \mathrm{~mL}$. The aqueous layer was also concentrated and transferred to another $100-\mathrm{mL}$ volumetric flask, and water was added to $100 \mathrm{~mL}$. The palladium concentrations in both volumetric flasks were measured using an atomic absorption spectrophotometer (Shimadzu, Kyoto, Japan, AA-7000), and no palladium species were detected. The solution was concentrated in vacuo. The residue was purified by silica gel column chromatography (hexane/EtOAc, 10:1) to give 4-acetyl-1,1'-biphenyl (1.94 g, $9.89 \mathrm{mmol}, 99 \%)$. 


\section{Conclusions}

We have developed a continuous flow Pd/C-catalyzed Suzuki-Miyaura coupling reaction under mild conditions. Aryl iodides smoothly underwent the coupling with various arylboronic acids. The reaction times required to complete the cross-coupling were only $20 \mathrm{~s}$ during the single-pass of the reaction solution through the catalyst cartridge. The present reaction provides a standard reaction conditions for the practical application of the flow Suzuki-Miyaura cross-coupling reaction between various aryl iodides and arylboronic acids.

\section{Acknowledgments}

We sincerely thank Zsolt Lepp, and CEO Richard Jones of ThalesNano Nanotechnology, Inc., and Yuko Kawahashi and Satoshi Ohtsu, Ikeda Scientific Co., Ltd., for their kind assistance and the lending of the H-Cube ${ }^{\circledR}$ continuous flow hydrogenator without charge. We highly appreciate the kind gift of $10 \% \mathrm{Pd} / \mathrm{C}$ by the N.E. Chemcat Corporation. Tomohiro Hattori thanks the Sasakawa Scientific Research Grant from the Japan Science Society for the partial financial support of this study.

\section{Author Contributions}

Hironao Sajiki, Yasunari Monguchi, and Tomohiro Hattori contribute to the experimental design. Tomohiro Hattori and Aya Tsubone contribute to all the experimental data collection. Tomohiro Hattori wrote the first draft of the manuscript that was then extensively improved by Yoshinari Sawama, Yasunari Monguchi, and Hironao Sajiki.

\section{Conflicts of Interest}

The authors declare no conflict of interest.

\section{References}

1. Miyaura, N.; Suzuki, A. Palladium-Catalyzed Cross-Coupling Reactions of Organoboron Compounds. Chem. Rev. 1995, 95, 2457-2483.

2. Nicolaou, K.C.; Bulger, P.G.; Sarlah, D. Palladium-Catalyzed Cross-Coupling Reaction in Total Synthesis. Angew. Chem. Int. Ed. 2005, 44, 4442-4489.

3. Kotha, S.; Lahiri, K.; Kashinath, D. Recent Applications of the Suzuki-Miyaura Cross-Coupling Reaction in Organic Synthesis. Tetrahedron 2002, 58, 9633-9695.

4. Luis, S.V.; Garcia-Verdugo, E. Chemical Reactions and Processes under Flow Conditions; RSC Publishing: Cambridge, UK, 2010.

5. Frost, C.G.; Mutton, L. Heterogeneous Catalytic Synthesis Using Microreactor Technology. Green Chem. 2010, 12, 1687-1703.

6. Noël, T.; Buchwald, S.L. Cross-coupling in Flow. Chem. Soc. Rev. 2011, 40, 5010-5029.

7. Gemoets, H.P.L.; Hessel, V.; Noël, T. Recent example for the flow reaction using homogeneous catalyst. Org. Lett. 2014, 16, 5800-5803. 
8. Hattori, T.; Tsubone, A.; Sawama, Y.; Monguchi, Y.; Sajiki, H. Systematic Evaluation of the Palladium-Catalyzed Hydrogenation under Flow Condition. Tetrahedron 2014, 70, 4790-4798.

9. Mennecke, K.; Kirschning, A. Polyionic Polymers-Heterogeneous Media for Metal Nanoparticles as Catalyst in Suzuki-Miyaura and Heck-Mizoroki Reactions under Flow Conditions. Beilstein. J. Org. Chem. 2009, 5, doi:10.3762/bjoc.5.21.

10. De Muñouz, J.M.; Alcázar, J.; de la Hoz, A.; Díaz-Ortiz, A. Cross-Coupling in Flow Using Supported Catalysts: Mild, Clean, Efficient and Sustainable Suzuki-Miyaura Coupling in a Single Pass. Adv. Synth. Catal. 2012, 354, 3456-3460.

11. Mateos, C.; Rincón, J.A.; Martin-Hidalgo, B.; Villanueva, J. Green and Scalable Procedure for Extremely Fast Ligandless Suzuki-Miyaura Cross-Coupling Reactions in Aqueous IPA Using Solid-Supported Pd in Continuous Flow. Tetrahedron Lett. 2014, 55, 3701-3705.

12. Glasnov, T.N.; Kappe, C.O. Toward a Continuous-Flow Synthesis of Boscalid. Adv. Synth. Catal. 2010, 352, 3089-3097.

13. Nöel, T.; Musacchio, A.J. Suzuki-Miyaura Cross-Coupling of Heteroaryl Halides and Arylboronic Acids in Continuous Flow. Org. Lett. 2011, 13, 5180-5183.

14. Shu, W.; Pellegatti, L.; Oberli, M.A.; Buchwald, S.L. Continuous-Flow Synthesis of Biaryls Enabled by Multistep Solid-Handling in a Lithiation/Borylation/Suzuki-Miyaura Cross-Coupling. Angew. Chem. Int. Ed. 2011, 50, 10665-10669.

15. Christakakou, M.; Shön, M.; Schnürch, M.; Mihovilovic, M.D. Arylation of Pyridines via Suzuki-Miyaura Cross-Coupling and Pyridine-Directed C-H Activation Using a Continuous-Flow Approach. Synlett 2013, 24, 2411-2418.

16. Maegawa, T.; Kitamura, Y.; Satoko, S.; Udzu, T.; Sakurai, A.; Tanaka, A.; Kobayashi, Y.; Endo, K.; Bora, U.; Kurita, T.; et al. Heterogeneous Pd/C-Catalyzed Ligand-Free, Room-Temperature Suzuki-Miyaura Coupling Reactions in Aqueous Media. Chem. Eur. J. 2007, 13, 5937-5943.

17. Cantillo, D.; Kappe, C.O. Immobilized Transition Metals as Catalysts for Cross-Couplings in Continuous Flow-A Critical Assessment of the Reaction Mechanism and Metal Leaching. ChemCatChem 2014, 6, 3286-3305.

18. Baghbanzadeh, M.; Pilger, C.; Kappe, C.O. Rapid Nickel-Catalyzed Suzuki-Miyaura Cross-Coupling of Aryl Carbamates and Sulfamates Utilizing Microwave-Heating. J. Org. Chem. 2011, 76, 1507-1510.

19. Gauchot, V.; Kroutil, W.; Schmitzer, A.R. Highly Recyclable Chemo-/Biocatalyzed Cascade Reactions with Ionic Liquids: One-Pot Synthesis of Chiral Biaryl Alcohols. Chem. Eur. J. 2010, 16, 6748-6751.

20. Kitamura, Y.; Sakurai, A.; Udzu, T.; Maegawa, T.; Tanaka, A.; Monguchi, Y.; Sajiki, H. Heterogeneous Pd/C-Catalyzed Ligand-Free Suzuki-Miyaura Coupling Reaction Using Aryl Boronic Esters. Tetrahedron 2007, 63, 10596-10602.

21. Li, X.-J.; Zhang, J.-L.; Geng, Y.; Jin, Z. Nickel-Catalyzed Suzuki-Miyaura Coupling of Heteroarylethers with Arylboronic Acid. J. Org. Chem. 2013, 78, 5078-5084. 
22. Subhas, M.S.; Racharlawar, S.S.; Sridhar, B.; Kennady, P.K.; Likhar, P.R.; Kantam, M.L.; Bhargava, S.K. New Cyclopalladated Benzothiophenes: A Catalyst Precursor for the Suzuki Coupling of Deactivated Aryl Chlorides. Org. Biomol. Chem. 2010, 8, 3001-3006.

(C) 2015 by the authors; licensee MDPI, Basel, Switzerland. This article is an open access article distributed under the terms and conditions of the Creative Commons Attribution license (http://creativecommons.org/licenses/by/4.0/). 